\title{
EL FUNCIONAMIENTO SOTERRADO DE LA CENSURA EN LOS MEDIOS DE PRENSA E IMPRENTA CONTROLADOS POR EL FRANQUISMO. ENTREVISTA A VICTOR MÁRQUEZ REVIRIEGO
}

\author{
Ramón Tena Fernández \\ Universidad de Extremadura, Cáceres, España \\ rtena@unex.es
}

Lo que escribimos unos periodistas suele ser para otros periodistas un bien mostrenco. Con estas palabras, Márquez Reviriego aludía en la presentación de su último libro, a la falta de rigor informativo con el que a veces se trata de documentar nuestro pasado histórico y cultural. Tras la publicación de Auténticas entrevistas falsas ha comprobado cómo las respuestas imaginarias que él mismo ha otorgado a sus "entrevistados" han sido tomadas por otros autores como auténticas citas verbalizadas realmente por ellos. Partiendo de esta premisa, reconoce que con frecuencia hay una mala interpretación de la memoria y eso obedece a los intereses personales del sujeto que investiga o del medio que publica sus resultados.

Sin embargo, sentencia que a pesar de la usurpación de la memoria que puede vivir el país, sus ciudadanos tienen gran libertad para expresarse en los medios de comunicación. El problema radica en que no siempre estamos dispuestos a asumir todas las consecuencias de nuestra libertad. Precisamente de los límites de la prensa e imprenta, así como también de su evolución en los últimos sesenta años, Márquez Reviriego puede aportar mucho más que una subjetiva reflexión. El periodista dispone de capacidad para acreditar y documentar el ambiente literario e informativo que vivía España cuando el cerco a letra impresa lo imponía el Estado y no el editor.

Nos referimos a la censura franquista, con la que tuvo que lidiar desde diversos frentes, no solo como autor de artículos, también por ejercer de redactor jefe de la revista Triunfo. Semanario que sufrió las sanciones económicas más elevadas que estipulaba la ley de 1966, junto con las suspensiones editoriales de mayor índole posible. No obstante, la valía de registrar la memoria de Márquez Reviriego no radica exclusivamente en su experiencia dentro de una de las redacciones más vigiladas por el Régimen, sino en la pluralidad de medios para los que trabajó y la variedad de funciones que desempeñó dentro del sector. 
Este bagaje laboral le ha dotado del conocimiento necesario para calibrar las diferentes actitudes de la censura en función del diario que publicara la noticia y la afinidad que este tuviese con el poder. Asimismo, también ha repercutido en que su discurso esté alejado de una visión unilateral marcada por la ideología concreta de una revista específica. Todo lo contrario, la narración de sus vivencias aporta una imagen global de la censura, en la que se definen obsesiones temáticas, tipología de correcciones, consignas y contradicciones a respetar. Se nos desvela la existencia de contenido vetado, el raciocinio de la censura para argumentar sus decisiones y las vías posibles para apelar ante errores evidentes.

Márquez Reviriego no solo aborda en esta entrevista la brutalidad cultural de la censura y su capacidad para obligar a la prensa a que secundara unánimemente sus decisiones, sino que con su testimonio pretende desmentir algunos mitos que históricamente han envuelto la historia de Triunfo y que, a base de repetirlos en numerosos medios, han sido tomados como verdades absolutas. Al día de hoy, algún nombre del panorama cultural y literario se vanagloria de haber trabajado para la que fue una de las revistas más influyentes en la oposición al franquismo. Sin embargo, su redactor jefe afirma con plena rotundidad que se atribuyen un mérito que no les corresponde, bien porque no formaron parte de la plantilla de la redacción, o bien porque nunca llegaron a escribir nada para ellos.

Conscientes de que la historia es un relato que se escribe desde el presente y eso indudablemente entraña tergiversaciones, consideramos vinculante abordar en las siguientes páginas tres secciones que ayudarán a comprender el comportamiento de la censura en general, y sus reacciones hacia Triunfo en particular. Por ello, iniciamos la entrevista interesándonos por las diferentes actitudes de la dictadura, continuamos abordando las particularidades de los reportes de Triunfo y finalizamos con el propósito de identificar las intenciones de su equipo redactor.

Precisamente, en lo que respecta a los integrantes de este núcleo podemos advertir, sin ningún género de duda, que quien supuso una pieza clave durante mayor número de años fue Márquez Reviriego. Por tanto, dar eco a los pasajes de su memoria es más que vinculante, necesario, para documentar una época que aún tiene abierto muchos interrogantes. Y que además, por extraño que parezca, pese a la relevancia de su nombre dentro de este campo, apenas le han hecho entrevistas sobre la censura y menos aún, con el detenimiento que se ha realizado en esta ocasión.

Por último, debemos reseñar que el prestigio del entrevistado no radica exclusivamente en la labor de prensa durante el franquismo. En la actualidad, publica periódicamente en la revista Leer, tiene en el mercado más de una docena de libros y se encuentra en ciernes del siguiente. Trayectoria que completa con su paso por los medios de comunicación nacionales más relevantes de España, entre los que pueden ser citados El País, $A B C$ o Diario 16 , sin olvidar tampoco que estamos ante uno de los fundadores de la revista Tiempo y el director adjunto de Cambio 16.

Por todo ello, el reconocido cronista parlamentario ha sido galardonado con el Premio Nacional de Periodismo, el Premio Espejo de España convocado por Planeta y el González Ruano, distinción que comparte con otros insignes como Arturo Pérez Reverte y Antonio Gala. Reconocimientos que se suman a la concesión de la medalla de Andalucía y a su nombramiento como Doctor Honoris Causa por la Universidad de Huelva. 
Muestra del interés que suscita nuestro entrevistado en el ámbito de la investigación lo prueba la tesis doctoral elaborada por José Romero Portillo, que versa sobre la crónica parlamentaria realizada por el periodista durante la Transición española y cuyos resultados doctorales fueron premiados por el Congreso de los Diputados en 2015. En definitiva, una trayectoria profesional reconocida institucionalmente, pero que precisa del registro de su memoria. Pues, al fin y al cabo ahí reside la justificación de sus galardones, en su amplia e impecable trayectoria profesional y cultural.

\section{ENTREVISTA:}

En primer lugar, comencemos por contextualizar su vinculación con Triunfo. ¿Qué puesto desempeñaba en su redacción y cuál era su relación con la censura?

- Yo entré a trabajar en Triunfo en julio de 1965, por tanto, aún estaba vigente la "Censura Previa" y era obligatorio consultar todo lo que queríamos publicar. Durante este tiempo y antes de ejercer como Redactor Jefe, mi puesto era solo de redactor. Como tal, además de por ser el nuevo, me destinaron a recoger periódicamente del ministerio las galeradas de la censura. En este sentido, algo curioso que muy poca gente conoce, a no ser que lo haya vivido, es que a ellos mismos parecía darles vergüenza de lo que allí dentro sucedía y no se entraba por la puerta principal del edificio. De hecho, cuando ibas a recoger las correcciones a lo que actualmente es el Ministerio de Defensa te entregaban las galeradas por la puerta de atrás, como a escondidas. La censura y su influencia en Triunfo aún tienen mucho por documentar. Es cierto que se ha publicado bastante, pero también lo es que existen muchas omisiones y esto no deja de ser desconocimiento.

\section{Ahondando en ese desconocimiento: Su biografía profesional no solo se reduce a Triunfo y seguro que puede aportar información de lo vivido en la redacción de otras revistas menos populares. ¿Tuvo algún incidente con la censura antes de llegar a Triunfo?}

- Sí, antes de todo esto, ya contaba con experiencia en materia de censura, pero como bien dices, estos periódicos y revistas no aglutinan una generosa bibliografía que analice su trayectoria. Yo trabajé nueve meses en el Odiel, de Huelva, que era el periódico de allí, sin embargo, como no era de ámbito estatal, el delegado del Ministerio de Información y Turismo tenía encomendado su control al director. Precisamente aquí, me quitaron un artículo completo y recuerdo que por buen criterio. Me explico, el director no era lo que se conoce como un fascista furibundo, pero yo hice una crítica sobre la época de los nazis. Tras su lectura el director me dijo que aunque estaba de acuerdo conmigo, también era conocedor de que el Régimen estaba aliado con esta gente. Por tanto, no era prudente que nosotros escribiéramos sobre el tema y el artículo directamente se desechó.

\section{Además de este tipo de censura delegada a nivel provincial ¿recibió alguna consigna o supresión en medios de ámbito nacional?}

- Antes de comenzar en Triunfo, también trabajé para Informaciones en el verano de 1964. Entonces los que estudiábamos periodismo en su escuela oficial podíamos desarrollar 
tres meses de prácticas durante el último curso, y yo escogí este periódico precisamente por ser el medio más pobre de Madrid. Es cierto que era la prensa de la Banca, pero sus medios eran escasos en comparación con los demás. De haber seleccionado $A B C$, por ejemplo, con seguridad lo único que hubiera hecho sería poner cafés a algún redactor veterano. Pero Informaciones tenía muy poca gente y eso ayudó a que todo el tiempo que estuve con ellos ejerciera como confeccionador, lógicamente aprendiendo. Este diario para el Régimen no entrañaba problemas; de hecho el director había sido capitán en la División Azul, era falangista y, por tanto, la censura focalizaba su atención en la sección internacional. Las incidencias venían desde esa dirección.

Pero, para entender el conflicto, previamente tenemos que contextualizar y describir las características de este periódico. Las páginas de Informaciones contaban en 1964 con un total de siete columnas, lo cual le confería un formato de sábana que le dotaba de un gran atractivo. Sin embargo, en la misma fecha, $A B C$ tenía tres columnas y El País, ahora cinco y La Vanguardia cuatro, mala cosa, pues nunca se deben tener cifras pares, porque la confección se convierte en monótona.

El incidente ocurrió en agosto de 1964 con la muerte de Palmiro Togliatti, líder comunista en la Unión Soviética; él junto a Antonio Gramsci fue uno de los dos más importantes que ha habido en la historia de Italia. En estos momentos - por las vacacionesyo estaba encargado de la confección del periódico. A pesar de conocer cómo actuaba la censura, le destiné cinco columnas y dos fotos. Tras la revisión del censor me devuelven el texto alegando que lo máximo que se podía eran dos columnas.

Lógicamente planteo que dos columnas en $A B C$ claro que era mucho, era suficiente, pero no para Informaciones que presentaba una estructura diferente. Al final, reducir cinco columnas a dos en una noticia importante, era como hacerla casi desaparecer. Era matar la relevancia de la noticia porque le restabas una importancia tremenda, y consciente de ello, traté de razonarlo. Pero no se podía con la censura. Este era uno de los aspectos más negativos, entre otras cosas porque no razonabas con el ministro, el subsecretario o ni tan siquiera el director general.

Entonces, ante una réplica urgente, como es el caso de un medio de comunicación
de periodicidad fija y sujeto a la actualidad ¿a quién le presentaba sus alegaciones? - Al que te ponían por delante, depende de la importancia del reclamante. Si hubiera llamado el director de Informaciones tal vez hubiese hablado directamente con el Jefe de Sección. En mi caso no fue así, el que me atendió sería seguramente algún funcionario subalterno y recuerdo que le dije: "Mire usted, si damos la noticia en Informaciones a cinco columnas es lo mismo que si se da en $A B C$ a dos, en cambio si aquí lo reducimos a esa cifra, la noticia queda en nada". Pues al final salió como ellos quisieron, un completo desastre.

Esto sucede en lo que se denomina tardofranquismo, pero hubo una época aún más brutal. Durante los años 40 y parte de los 50, no solo tachaban el contenido, también te obligaban a que publicases sus consignas. Luego eso se dulcificó y te pedían que publicaras algo, pero no te obligaban. A Ezcurra (director de Triunfo) lo llamaron con motivo de la Ley Orgánica de 1966 por si podía escribir algo al respecto en la revista, 
algún reportaje, artículo algo por el estilo, como para darle publicidad, o sacar a Franco en portada. Y nos limitamos a publicar el texto íntegro de la Ley.

\section{¿Había alguna distinción gráfica o artística entre un artículo exigido por el Régimen y otro de carácter voluntario? ¿EI lector podía diferenciarlos?}

- No, nada. De hecho esos artículos se llamaban en la jerga periodística "textos de inserción obligatoria", eran dirigidos normalmente para los diarios. Pero bueno, es que los periódicos eran casi todos afines al Régimen, de lo contrario no hubiesen contado ni con autorización para su creación. Es más, la censura mandaba el artículo escrito ya por ellos mismos, con las palabras exactas de lo que tenías que publicar. Era un texto sin modificaciones posibles, o sea, que no dejaban lugar a interpretaciones, ni a que tú tacharas este párrafo o cambiaras tal palabra, lo publicaba "todo Cristo" y tal cual estaba.

Entiendo que en los últimos años se trataba más bien de sugerencias. No obstante, la pregunta es clara ¿no aceptar estas ideas conllevaba repercusiones negativas?

- Eso depende. Las dictaduras son bastantes ambiguas, son muy claras en algunas cosas, pero no en otras y de ello se retroalimentan y benefician. A veces, en una editorial te permitían publicar un libro y, sin embargo, ese mismo contenido era imposible para otras editoriales, porque sencillamente la censura así lo consideraba. Prueba de esta sin razón es lo sucedido en el diario Madrid en los años cuarenta, donde la redacción recibió la consigna de que cuando informara de uno de los viajes que Franco iba realizar esa misma semana, escribiesen que "las campanas doblaron de alegría con la llegada del caudillo". Montero Alonso, un veterano periodista de los años veinte les dijo "Oigan, cuando las campanas doblan, doblan por tristeza por un muerto; de alegría lo que hacen es repicar". A lo que el censor de turno le respondió “Aqui pone doblar, que doblarán y el periódico pondrá que doblaron". Entonces, éste hizo una cuarteta que no se publicó naturalmente, era más bien de desahogo, pero que merece la pena recordar porque define muy bien toda esta situación. Decía, lo siguiente:

El doblar que es toque serio

se hace toque de optimismo

si lo ordena el Ministerio

de Información y Turismo.

¿Este tipo de discusiones siempre las hacía el director de la revista o las podía hacer directamente el autor del artículo? Y lo más importante ¿existieron tachaduras verbales o todo quedaba registrado en informes oficiales de censura?

- En el caso que he expuesto de las columnas de Informaciones, lo hice directamente yo y por teléfono, pero claro que logré solo comunicarme con alguien de muy poca relevancia dentro de la administración y no conseguí absolutamente nada. Lo mismo sucedió con el caso de las campanas, que finalmente se publicó que doblaron de alegría, otro sin sentido. O sea, que era muy difícil discutir con ellos y más aún llegar a algún entendimiento lógico.

Las negociaciones verbales sí que existieron, pero no para mí, ni tampoco para el equipo de Triunfo que mantenía relaciones muy distantes con la censura. Esto lo podía hacer, 
por ejemplo, el director de $A B C$, Juan Ignacio Lucas de Tena, que aunque monárquico, fue quien pagó el avión para que Franco llegara a Marruecos desde Canarias cuando la guerra y esto lo tenían en cuenta. Realidad bien distinta es la que envolvía a Triunfo, reconocidos como rojos y, por ende, merecedores de un trato diferente.

A mí me contó Ezcurra (director de Triunfo), que en una cena de los premios Mariano de Cavia y Luca de Tena de $A B C$ en la época del ministro Arias Salgado, Torcuato Luca de Tena (hijo del marqués Juan Ignacio y director de $A B C$ ), junto con Gonzalo Fernández de la Mora (diplomático) criticaron personal y duramente al ministro. Esto te evidencia que era más importante el marqués que el responsable del ministerio. En las dictaduras lo personal cuenta mucho porque estas son arbitrarias. Otra prueba la tienes con el marqués de Villaverde que realizaba trasplantes de corazón y poco importaba lo que sucediera en el proceso, sencillamente porque era el yerno de Franco y con eso bastaba.

\section{Después de ejercer en el Odiel como redactor y en Informaciones como confeccionador} ¿comenzó en Triunfo o tuvo experiencia en otros medios de prensa escrita?

- También estuve en Sábado Gráfico y más tarde trabajé unos meses para el diario Arriba, del cual me marché. Yo estaba de auxiliar de confección, entraba en talleres a las once de la noche y terminaba a las cuatro de la madrugada. Mi ocupación era resolver alguna duda, y si llegaban tachaduras de la censura el encargado de cortar esas líneas era yo.

A veces se originaban malos entendidos, por ejemplo, allí en una ocasión se metieron con Aranguren en un artículo, y éste mandó al día siguiente una réplica que el periódico aceptó. No sucedió lo mismo con la censura, que ordenó que eliminaran la réplica y por tanto, Aranguren quedó como que acataba lo dicho en el periódico o que se achantaba ante él y fue todo lo contrario.

De todos modos, en Arriba suprimían muy poco, yo no recuerdo que tacharan prácticamente nada. Me imagino que suprimían más en $A B C$, aunque aquí seguramente las cuestiones de censura las trataría el director por vía directa con el ministro, porque eran cosas desde la derecha y a favor de la monarquía. De todos modos, estos procedimientos no eran propios de Triunfo; como prueba de ello puedo explicar que a nosotros nos rechazaron un reportaje turístico sobre Moscú, hablando de los zares y no de la revolución, y lo tacharon íntegramente.

Sin embargo, si nuestro director lo hubiera negociado, seguramente habría sido admitido, pero no se intentó. Con ello, lo que quiero expresar es que este mismo reportaje dentro de $A B C$ hubiera pasado sin problemas porque a veces no era tan importante el contenido, sino el periódico o la revista que lo presentaba.

Su recuerdo de Arriba concuerda con lo que han verbalizado otros entrevistados. De hecho, Forges nos confesó que sus viñetas más controvertidas las publicó aquí porque la censura consideraba que ya la dirección ejercía su propio expurgo. ¿Era más fácil publicar contenido crítico precisamente en un periódico afín al poder?

- Sí, sin duda, la vigilancia que se ejercía aquí era completamente distinta a la que se podía hacer en otros medios. En Arriba sucedía lo contrario a lo que se vivía en Triunfo, donde indudablemente había más ojos pendientes de lo que se publicaba. Hasta la página que hacía Enrique Miret Magdalena destinada a asuntos religiosos era mirada con lupa, 
él era progresista y eso "jorobaba". No gustaban sus textos con ideas contrarias a las que publicaban gente como el padre Venancio Marcos, que era de extrema derecha, más oscuro y menos tolerante con los intentos de apertura.

Dentro de los contenidos y secciones de la revista es patente que se centraban más en lo internacional que en lo nacional. En este sentido ¿considera que hubo alguna evolución?

- Siendo nosotros de izquierda, en Triunfo las noticias nacionales eran prácticamente imposibles de abordar. No podíamos hablar de temas como el Consejo Nacional del Movimiento y decir abiertamente que aquello era una farsa, pero sí podías hacer reportajes muy vivos, pero por miedo o cautela apenas se hacían. De hecho, yo hice uno sobre Gibraltar donde en vez de tratar el tema de forma "patriótica", lo hice hablando de los problemas laborales que originaría el cierre de la verja fronteriza. Y otro sobre el pueblo de Gibraleón, donde había un barrio de mestizos, familias que venían de la época del imperio español, descendientes de esclavos y por ahí metí todo lo que no podíamos escribir de manera clara.

De todo esto hay dos conclusiones: la primera es que en lo nacional había que tener mucho cuidado, la censura no dejaba pasar ni una. Y la segunda es que el control habitualmente era más fuerte en los diarios que en las revistas. La mayoría de ellas vendían unos 50.000 ejemplares, mientras que un diario podía llegar fácilmente al doble; y también, por una cuestión de cifras, se vigiló con mayor dureza al cine que al teatro. Los censores podían ser brutos en su mayoría, pero la censura como institución no era tonta.

Indica que algunos - como Alonso de los Ríos, Carandell, Vázquez Montalbán y ustedlucharon seriamente por abordar contenido nacional en la revista, pero desconozco la intención. ¿Se trataba de informar, denunciar actos o destapar temas silenciados?

- Destapar no destapamos nada, porque no tratábamos los temas nacionales, entre otras cosas, porque no podíamos. Día a día no podías hacer un reportaje de investigación, mucho menos usar información veraz y datos reveladores. Si querías abordar algo controvertido tenías que ir por la vía indirecta.

Mostrar lo negativo de una situación también se puede hacer evidenciando las bonanzas de lo que sucede fuera de nuestras fronteras y en Triunfo destinaron páginas completas a lo internacional. ¿Se buscaba este fin?

- Claro que ayudaba, lo mismo que ayudó luego la televisión, el peligro para las dictaduras, que hizo ver a la ciudadanía que existían parlamentos libres. En lo internacional, por supuesto, que defendíamos políticas de izquierdas, y de hecho en la guerra de Vietnam no nos situamos precisamente con los americanos. No todo lo que hicimos fue correcto, también nos equivocamos. Ezcurra y Haro, por ejemplo, fueron muy críticos con Charles de Gaulle (presidente de la República Francesa). Se escribía sobre él con carácter francólogo, o sea que cuando se hablaba de él parecía que se hacía de Franco. Nada que ver si valoras que De Gaulle perdió un referéndum libre y se marchó. Algo que con Franco no hubiese sucedido nunca. 
Cuando se arriesgaba a escribir sobre un tema nacional ¿empleaba algún recurso especial con el que protegerse de las consecuencias de la censura?

- Para abordar los temas nacionales me apoyaba en una especie de metalenguaje. Por ejemplo, en vez de hablar de la problemática de Gibraltar, lo hacía describiendo las situaciones sociales de sus habitantes, sus dificultades. Así conseguía mostrar las consecuencias de un conflicto que no mencionaba. Pero hasta esto me reportaba consecuencias, como sucedió con el reportaje “Gibraleón, los negros andaluces”. Este reportaje me costó que me declararan persona non grata y que incluso me amenazaran. Pero sobre todo no era solamente por la denuncia social, sino porque hablaba aportando apellidos concretos. Ahí tienes la prueba de las consecuencias de optar por la vía directa, y para nada esto supuso un caso aislado. Algo parecido le sucedió a mi compañero César Alonso, que escribió sobre Bercianos de Aliste, un pueblo del Bierzo, y el cura respondió redactando una carta en la que lo tachaba de ateo.

Los temas catalogados de inadmisibles como el contenido erótico, la homosexualidad o la crítica a los ministros del Estado y la iglesia ¿eran imposibles de abordar o solo si se ubicaban en España?

- Todo era aleatorio. Normalmente, un asunto que se refería a españoles no era tolerado, y acaso era permisible si se refería a otros países. A veces las correcciones que imponían agudizaban paradójicamente aún más aquello que querían silenciar, y esto lo puedo ejemplificar con un hecho totalmente verídico. Se trata de la película Mogambo; en ella salían escenas de infidelidad, y resulta que para que no hubiese tal adulterio cambiaron en el doblaje la palabra matrimonio para meter una supuesta relación de hermanos. De este modo el marido no era infiel, sino más bien excesivamente amoroso con la hermana; vamos que cambiaron sin darse cuenta una infidelidad por un incesto evidente. La censura era muy arbitraria, pero como casi cualquiera que hubiese estado en sus filas. No nos engañemos, todo el que tiene poder absoluto termina actuando con brutalidad, porque no necesita razonar.

Una vez contextualizado sus avatares con la censura y su trayectoria en prensa es el momento de centrarnos en Triunfo. La bibliografía especializada ha centrado sus investigaciones en torno a los mismos nombres, los identificados como máximos responsables de la revista. Pero, la historia no siempre es justa y a veces nos olvidamos de otros protagonistas relevantes. ¿Quiénes hicieron Triunfo?

- Hacer entrevistas es vital para documentar este tipo de cuestiones, pues, una cosa es lo que aparece en los créditos de la revista y otra, a veces muy diferente, saber quiénes realmente trabajaron en ella. Con esto lo que quiero decir es que la gente no sabe que Triunfo la hacíamos entre unos pocos, muy pocos, lo que sí contábamos era con muchos colaboradores. En primer lugar, estaban el director, José Ángel Ezcurra, que no escribía nunca y el subdirector Haro Tecglen, que por el contrario se dedicaba a escribir mucho. A la redacción solo venía una hora y media antes de comer para hablar tanto con el director como con Alonso de los Ríos y yo (redactores jefes). En segundo lugar, debemos hacer mención a Vázquez Montalbán, que estaba en Barcelona y aunque lo normal es encontrarse su mención bajo el epígrafe de "Colaboración y redacción” es mentira, era mucho más 
que un colaborador al uso. También se debe saber que por ejemplo Juan Aldebarán, que figura como colaborador, en realidad era un seudónimo del subdirector Haro Tecglen, por tanto, figuraba más veces en los créditos, con otros seudónimos.

Por otra parte, hubo una amplia nómina de participantes que no estuvieron en la redacción, aquí puedo citar a Luis Carandell, que hacía la sección "Silla de Pista," y el célebre "Celtiberia Show", Ramón Chao, que estaba en París o Chumy Chúmez, que hacía los dibujos pero desde su casa. Del mismo modo procedieron tantos otros, como Pablo de la Higuera, que enviaba su trabajo desde Francia, o Arturo López Muñoz (sección de economía), que nos visitaba una vez a la semana para entregar su texto, al igual que sucedió con José Monleón (sección de teatro), Moreno Galván (sección de arte) y Ricardo Zamorano (dibujos).

Con esta lista de nombres pretendo manifestar que fueron muchos los participantes; pero, dentro, la armazón de la revista la hacíamos prácticamente entre César Alonso de los Ríos y yo.

Como miembro activo de la revista seguro que puede hablar con conocimiento de causa. ¿Notó cambios sustanciales dentro de los fines marcados por la dirección?

- Hombre, la revista se fue haciendo. Triunfo fue evolucionando por el impulso de los lectores, por las propias circunstancias históricas que fueron permitiendo que se pudiera hablar más y, cómo no, por la constancia de los que estábamos dentro. De hecho, en Triunfo había dos grupos, sobre todo a partir de la nueva Ley de Prensa e Imprenta de 1966: los que querían que las cosas se mantuvieran como estaban y los que apretábamos para que la revista se ocupara de asuntos nacionales. En el primer grupo se situaban Ezcurra y Haro (director y subdirector), mientras que en el segundo estábamos Nicolás Sartorius, César Alonso y yo. Era un caso de dos generaciones: los mayores y los jóvenes.

Sorprende la intención inmovilista de la dirección, si tenemos en cuenta que Ezcurra definía la revista como progresista y en continua resistencia intelectual al franquismo. ¿Con qué argumentos esgrimía mantenerse en la misma línea?

- Quizás el problema estaba en la idea algo distorsionada que Haro Tecglen tenía de España. Él pensaba que el país no había cambiado nada y lo cierto es que la diferencia del Madrid que él había conocido en los años cuarenta cuando marchó a París, nada tenía que ver con el que se vivía en la época de Triunfo. Él creía -pongamos por caso- que en España se editaban unos 3.000 títulos, como entonces, cuando por aquel momento la cifra superaba ya los 40.000. Tengamos en cuenta que el país, a pesar de su dictadura, había cambiado mucho. La España de los años cuarenta se alejaba bastante de la realidad de los sesenta, y sirvan como ejemplo esas cifras de edición editorial, que se multiplicaron considerablemente a medida que pasaba el tiempo.

Durante los últimos años de Franco, la eclosión y explosión editorial fue tremenda, se editó más del marxismo en este tiempo que en toda su historia, entre otras cosas porque estuvo muy de moda. Se publicaban obras de hasta dos tomos con pastas duras y próximas a las mil páginas. Pero, conocedores de este cambio editorial e interés social éramos los que vivíamos aquí y trabajábamos en el medio. Sin embargo, Haro Tecglen, nuestro subdirector, era un periodista de posguerra que había empezado muy joven en 
Informaciones y además estuvo de corresponsal en París y de director en Tánger. Por ello, la realidad que había conocido era diferente a la nuestra y eso fomentaba una visión diferente sobre cómo afrontar la continuidad de la revista.

\section{¿Cómo intentaron favorecer ese cambio editorial de la revista?}

- Triunfo era una revista hecha por un equipo de colaboradores jóvenes, y eso se debe a que César Alonso y yo también lo éramos en ese momento y, por tanto, conocíamos a gente similar que empezaba a despuntar en diversos sectores. A ellos era a los que tratábamos de fichar, y como ejemplo puedo citar a Julio Segura y García Delgado, que acabaron siendo catedráticos, o Santiago Roldán que se convirtió en rector de la Universidad Internacional Menéndez Pelayo.

Ezcurra no conocía entonces a la mayoría de ellos y Haro se había quedado anclado en el pasado y eso favorecía números menos frescos. Tenía capacidad para frenar o no publicar algo si le despertaba ciertas reticencias, por ello nosotros que conocíamos a la gente ejercíamos como impulsores. Otras veces no hacía falta esta defensa, como sucedía con los textos que presentaba Vázquez Montalbán. Aunque en un principio no convencieran del todo a Haro Tecglen, -como la "Crónica sentimental de España"finalmente se publicaban porque Vázquez Montalbán tenía tanta calidad y tanta fuerza que siempre se imponía por sí mismo.

También se favorecía incluir a savia nueva en los dibujos y OPS era uno de los que más me interesaban. No lo pude meter en el año 1966, porque creo recordar que por aquellas fechas tendría unos diecisiete años. En el verano de 1970 sí lo conseguí y recuerdo que fue para unas páginas especiales de Consumiendo vacaciones, que fue el germen de los números extraordinarios. En ese -primero de todos ellos-participó OPS con dos ilustraciones que todavía eran chistes, no sátira muda como la que hizo tiempo después, el asunto era Neptuno vendiendo Coca-Colas en la playa.

OPS, que actualmente es $E l$ Roto, fue uno de los nombres más castigados en las evaluaciones de los censores. De hecho nos ha reconocido en una entrevista previa que por uno de sus dibujos tuvo que responder ante un juicio militar. ¿Fue complejo convencer a la dirección de la idoneidad de su inclusión en la revista?

- Con nosotros ya trabajaba en la redacción Joaquín Rábago, el hermano mayor de OPS, una persona muy culta. Joaquín entró en el año 1965, poco después de entrar yo; de él se tuvo en cuenta su gusto por la lectura y el dominio del inglés, francés, alemán y algo de ruso, total que ejerció de traductor en Triunfo. OPS no necesitaba aval porque se fue imponiendo por su gran calidad e iba evolucionando su tipología de dibujo en cada número de la revista. OPS empezó a ver libros sobre Magritte, y seguramente de todos los pintores que existen este fuese el que más le influyera.

De hecho, hay una época de OPS que era Magritte puro, que era mudo, él solo sugería y eso bastaba. Ahora en cambio, para El País cómo ha evolucionado a "El Roto", siempre acompañan sus viñetas con alguna frasecita, pero esto se aleja de lo que hacía para nosotros. En lo que concierne a las viñetas e ilustraciones, tuvimos -entre otros muchos- a tres excepcionales autores: El humor de Chumy Chumez que era como 
el Aristóteles o Cervantes de su gremio, algo así como el padre de todos, OPS que era como Quevedo y Saltés, nuestro Góngora de línea fina.

\section{¿Las viñetas al contener dibujos y textos eran más difíciles de publicar? ¿Suponía una doble revisión?}

- Durante una época que atañe a los años de la "Censura Previa", la obligatoria, nos situamos ante la censura más cerril y la propiciada por la Iglesia. Valga como ejemplo que desde ella se instaba a cubrir todos los escotes de los dibujos. Recuerdo que en $A B C$ de Sevilla, un amigo mío, buen dibujante, estaba especializado en achicar los escotes de las fotos, se dedicaba a taparlos. Lo mismo que en televisión había un chal de emergencia para cubrirlos ante los espectadores, si era preciso. Esas cosas eran de la Iglesia. La Iglesia española durante este tiempo tuvo, por lo general, una actitud muy hipócrita, a pesar de que también hay que reconocer luego el mérito de algunos nombres, como el cardenal Tarancón y un grupo de curas progresistas que no comulgaron con esto.

\section{UNAS LÍNEAS FINALES A MODO DE CONCLUSIÓN}

Con entrevistas como las de Márquez Reviriego se logra mucho más que hacer un recorrido biográfico por la trayectoria profesional de una celebridad cultural, de gran relevancia para el ámbito literario y periodístico. Con su testimonio hemos podido contribuir a documentar parte de una época histórica repleta de silencios, tachaduras, correcciones e información falseada por medio de consignas impuestas por el gobierno. Si no fuese por el cotejo comparativo entre la información oficial, y la vivida por los autores que se sometieron a la censura, estaríamos condenados a dar por certeros unos datos sesgados por un régimen que confiaba su permanencia en el poder en la capacidad adoctrinadora de la prensa y la propaganda.

Sin embargo, este ejercicio documental que requiere de archivos y entrevistas, no siempre es factible. Primero, porque ya han desaparecido centenares de informes de censura y, segundo, porque evocar el recuerdo de épocas oscuras como la dictadura franquista, no es un ejercicio al que todos los autores estén dispuestos. Lograr una entrevista como la de Márquez Reviriego no es nada sencillo, pues como se puede valorar en páginas anteriores, el periodista habla con total claridad de la manipulación periodística, muestra evidencias en los hechos que describe y especifica a lo largo de su relato nombres y datos concretos de gran relevancia para comprender el contexto y la época.

Gracias a lo que el cronista parlamentario nos ha documentado, conocemos con mayor precisión las diferencias reales entre la ley de prensa de 1938, elaborada en medio de la Guerra Civil, y la de ley de 1966, enmarcada en el tardofranquismo. Y además, fruto de su amplio bagaje periodístico queda claro que lo relevante no siempre fue la censura, sino el medio en el que se publicaba y quién firmaba el artículo. Él nos ha aportado ejemplos concretos de cómo el contenido más controvertido que lograba editarse en España era precisamente el que se presentaba a la prensa afín al poder, simplemente 
porque la censura confiaba en la lealtad política de los directores de estos medios y por consiguiente la vigilancia institucional era escasa o nula.

No obstante, esta situación era muy distinta a la que Márquez Reviriego vivió durante sus años como redactor jefe en Triunfo, un semanario de izquierdas, en el que fue preciso emplear un metalenguaje específico para poder publicar, anteponer el contenido internacional frente al nacional y aceptar las sanciones más severas que podía imponer el órgano censor. Una administración ante la que siempre hubo que ceder, sin importar en absoluto que sus consignas y "correcciones" fuesen totalmente incoherentes y disparatadas, pues como el mismo entrevistado concluye, los censores podían ser brutos en su mayoría, pero la censura como institución no era tonta. 